\title{
GANGRENA GASOSA - ASSISTENCIA DE ENFERMAGEM
}

\author{
* Maria Lúcia Toledo Vasco \\ ** Edna Rodrigues
}

$\mathrm{RBEn} / 03$

VASCO, M.L.T. e RODRIGUES, E. - Gangrena gasosa - Assisténcia de enfermagem.

Rev. Bras. Enf.; DF, 30 : 244-253, 1977.

\section{INTRODUÇAOO}

A maioria dos pacientes em tratamento nas várias unidades de internaçōes do hospital que apresentem uma infecção suspeita ou clinicamente diagnosticada como gangrena gasosa sāo transferidos para a unidade de isolamento da Clínica de Moléstias Infecto-Parasitárias do Hospital das Clínicas.

A incidência de gangrenas de etiologias diversas no decorer de 1975 em todo o hospital, de acordo com um levantamento feito pelo Serviço de Arquivo Médico e Estatístico foi de 126 casos. Deste total 7 casos $(5,55 \%)$ foram clinicamente diagnosticados como gangrena gasosa e transferidos para a unidade de isolamento.

Como, no decorrer de 1975 estivesse em andamento uma pesquisa programada pelo grupo de Trabalho de Controle de Infecçōes do hospital sobre a incidência de infecçōes por germes anaeróbios, foram realizados testes laboratoriais específicos em 6 dos 7 pacientes isolados com tal afecção.

O diagnóstico de gangrena gasosa foi confirmado em apenas 2 casos com a recuperação no laboratório. dos agentes etiológicos dessa afecção: germes anaeróbios do gênero Clostridium.

A espécie dos mesmos ainda não foi classificada visto os exames estarem em fase de conclusão laboratorial.

Na Tabela I, em anexo, estão especificados o local da lesão, o agente etiológico, a evolução da moléstia, o sexo, a cor, o número de dias de permanência, e o periodo de incubação dos 7 pacientes estudados.

\section{CONSIDERACOÓES GERAIS}

Sabe-se que a gangrena gasosa é uma complicação séptica de ferimentos com

- Enfermeira da Clinica de Moléstias Infecto-Parasitárias do Hospital das Clínicas da FMUSP.

* Enfermeira do Grupo de Trabalho de Controle de Infecçōes ao Hospital das Clínicas da FMUSP. 
VASCO, M.L.T. e RODRIGUES, E. - Gangrena gasosa - Assistência de enfermagem.

Rev. Bras. Enf.; DF, $30: 244-253,1977$.

oxigenação precária (baixo potencial de oxiredução local) e condiçōes de anaerobiose capazes de permitir a franca multiplicação de germes do gênero Clostridium, os quais passam a elaborar toxinas hemoliticas e necrotizantes.

\section{A - Condições favoráveis à infecção}

A simples presença dos agentes etiológicos no local dos lesōes não é suficiente para se diagnosticar a infecção; é necessário que o germe encontre condiçōes favoráveis para que possa se desenvolver.

Estas condiçōes caracterizadas como anaeróbicas são mais frequentes em:

1 - Infecçōes por corpos estranhos e por substâncias irritantes.

2 - Em abscessos causados por outros tipos de germes.

3 - Áreas de isquemia e irrigaçāo deficiente.

4 - Áreas necróticas e outras.

\section{B - Localização e caractísticas}

As infecçōes por clostridio localizadas no tecido muscular ou cutâneo, podem ocasionar miosites e celulites. As miosites podem ser disseminadas (difusas) e localizadas. Ambas podem ser crepitantes oì não.

Não só nos ferimentos de pele e músculos pode-se instalar uma gangrena gasosa, mas também em diferentes vísceras, ocasionando gangrenas pulmonares, ápendicites gengrenosas. gangrenas intestinais, uterinas e outras.

A Tabela II em anexo, diferencia as infecçōes gasosas de pele e tecidos moles.

\section{C - Agentes etiológicos}

Os diferentes agentes causadores da gangrena gasosa pertencem ao gênero Clostridium. Estes são bacilos Gram positivos que esporulam em condiçōes adversas e assumem formas bacilares (vegetativas). Quando em condiçōes anaeróbicas, passam a elaborar as exotoxinas responsáveis pelas lesões encontradas nos tecidos superficiais, as quais mais tarde se estendem às estruturas mais profundas.

Das 18 espécies de germes do gênero Clostridium causadores da gangrena, as nais freqüentes são:

- Clostridium perfringens (Clostridium welchii).

- Clostridium novyi (Clostridium oedematiens).

- Clostridium bifermentans (Bacillus bifermentans sporogenes).

- Clostridium sordelil (Bacillus oedematis sporogenes).

- Clostridium histolyticum.

- Clostridium sporogenes.

O clostrídio existe no solo, no tubo digestivo dos animais e do homem, e pode ainda ser encontrado na lā.

$\mathrm{D}-$ Modos de transmissão, periodo
de tncubação, susceptibilidade

Transmite-se através dos tecidos necrosados e secreçōes de um paciente infcctado; da poeira, do solo e das fezes contaminadas.

O periodo de incubação pode variar de algumas horas até 5 ou 6 dias.

Quanto à susceptibilidade não há resistência natural.

\section{QUADRO CLINICO, DIAGNÓSTICO E TRATAMENTO}

Geralmente o primeiro sintoma é a dor local. Surge depois o edema que aumenta rapidamente com a formação de gases quie são evidenciados à palpação pela crepitação ou através de exame radiológico do local.

Visualmente nota-se a pele tensa, brilhante, de coloração marrom-bronze; 
VASCO, M.L.T. e RODRIGUES, E. - Gangrena gasosa - Assistência de enfermagem.

Rev. Bras. Enf.; DF, 30 : 244-253, 1977.

surgem com freqüência flictenas que se rompem, dando saída a líquido serosanguinolento de odor fétido.

f de vital importância o diagnóstico precoce para a instalação de medicação especifica. Entretanto ao exame clínico a simples presença de crepitação não conduz obrigatoriamente ao diagnóstico de gangrena gasosa uma vez que infecçōes por outras bactérias, como por exemplo, o aerobacter e a escherichia podem produzir gases.

Entre os exames de laboratório, temos como mais importantes para a confirmação do diagnóstico os seguintes:

- Cultura pelo meio anaeróbio (com $\mathrm{CO}_{2}$ ).

- Exame direto de esfregaço corado pelo método de Gram. através do qual se verifica a presença de bastoneles Gram positivos em grande quantidade.

- Hemocultura em meios anaeróbios e aeróbios.

- Inoculação em cobaias.

- Hemograma, o qual revela anemia sem leucocitose.

- Exame radiológico que evidencia a presença de gases acompanhando os músculos e interstícios.

O sucesso do tratamento, como já foi mencionado, consiste no diagnóstico precoce e conduta terapêutica imediata. Quando houver indicação, deve-se debridar e extirpar o foco infeccioso para 8.nular a fonte produtora de toxinas.

A terapêutica medicamentosa especifica é realizada através de soro antigangrenoso (anexo II) e antibióticos (Penicilina cristalina, Penicilina G potássica, Clindamicina e Cloranfenicol); medica-se sintomaticamente pela sedação da dor quando necessário.

A partir de 1963 , o uso da oxigenaçāo hiperbárica (câmara com oxigênio sob pressão de até 3 atmosferas) em pacientes com gangrena gasosa, parece ter mudado o prognóstico em determinados ca- sos, dispensando às vezes, intervençōes mutilantes e permitindo rápida melhora clínica, com supressão quase imediata da produção de toxinas.

Não temos experiência pessoal deste tratamento em nosso meio, pela inexistência de equipamento necessário para tal tipo de tratamento.

\section{ASSISTENCIA DE ENFERMAGEM}

A menor suspeita de gangrena gasosa ou qualquer outro tipo de gangrena, deve-se imediatamente isolar 0 paciente e instalar-se o uso de técnicas específicas de isolamento.

O tratamento pode ser efetuado na própria unidade em que se encontra o paciente (médica ou cirúrgica), não necessitando obrigatoriamente de ser encaminhado à unidades de isolamento, desde que 0 ambiente do paciente ofereça todas as condiçōes para que possam ser observados todos os princípios e técnicas assépticas mencionadas no decorrer deste trabalho (anexo I).

$A$ base da assistência de enfermagem fundamenta-se no reconhecimento dos sinais e sintomas que caracterizam a moléstia, e no estabelecimento de prioridades para 0 atendimento.

E muito importante a observaçāo do período de incubação médio entre a injúria e o desenvolvimento da lesão, o qual é de mais ou menos 53 horas.

Observa-se aumento da freqüência cardíaca, sendo que os valores médios oscilam em torno de 118 batimentos; a P.A. arterial é geralmente normal no início. mas no decorrer da moléstia, veriffica-se hipotensão. A taquicardia associada à hipotermia é geralmente sinal de mau prognóstico. Observa-se crepitação e dor local, quando se faz o curativo e uma cor peculiar com marrombronze na pele ao redor da lesão. A hipertemia e edema local sāo frequientes. Observa-se ainda sudorese, palidez acin- 
VASCO, M.L.T. e RODRIGUES, E. - Gangrena gasosa - Assistência de enfermagem.

Rev. Bras. Enf.; DF, $30: 244-253,1977$.

zentada, além dos sinais de toxemia. O estado mental apresenta-se alterado. 0 paciente pode ficar apático ou incoerente. Delírio, prostaçāo e coma podem ser sintomas latentes.

O plano assistencial de enfermagem deve ser individualizado, diário, elaborado pela enfermeira, sintetizando o atendimento a todas as necessidades físicas, psicológicas, sociais e religiosas do paciente.

Inicialmente faz-se a entrevista com o paciente no momento de sua admissāo na unidade de isolamento, posteriormente faz-se o levantamento de suas necessidades e elabora-se o plano assistencial.

A - Plano assistencial de enfermagem - Condições a serem observadas

1 - Nível de consciência:

Observar, anotar e comunicar as alteraçōes do nível de consciência. $O$ paciente pode estar consciente, inconsciente, apático, confuso ou delirante.

2 - Condiçōes de locomoçāo e movimentaçāo:

Estas condiçōes estão afetadas e quase sempre o paciente está restrito ao leito. Mantê-lo em repouso absoluto, em posiçāo anatômica e funcional. Para a prevençāo de escaras e deformidades prescrever mudanças de decúbito de acordo com o tipo de lesāo e local afetado; prescrever massagens de conforto.

3 - Condiçōes de higiene:

O estado geral e a limitaçāo física indicam a prescriçāo de banho no leito, higiene ocular com água boricada a $2 \%$ e higiene oral com água bicarbonatada a 2\%. Devem ser observadas as condiçōes da pele e mucosas. Programar a troca da roupa de cama várias vezes ao dia para manter o paciente limpo e seco.

4 - Condiçōes das funçōes vitais:

Programar o controle dos sinais vitais, TPR e PA, de $4 / 4$ horas, ou de acordo com a necessidade do paciente. Manter o médico informado quanto à elevaçāo da freqüência cardiaca, elevaçāo ou queda da temperatura e queda da pressāo arterial.

5 - Condiçōes de hidrataçāo:

Observar os sinais clássicos de desidrataçāo, prescrever controle de líquidos ingeridos e eliminados, oferecer água e sucos em grande quantidade. A diminuiçāo do volume urinário, oligúria ou anúria, indica a necessidade da sondagem vesical de demora para um controle mais eficiente.

6 - Condiçōes de nutriçāo:

Programar com a nutricionista dietas alimentares em adequaçāo com a prescrição médica e as necessidades calóricas do paciente e suas condiçōes para aceitaçāo. Oferecer dietas leves no início, seguindo as preferências do paciente. Nos primeiros dias, de acordo com o quadro clínico do paciente pode ser observado jejum. As vezes é necessária a sondagem gástrica quando houver vômitos constantes ou inconsciência.

7 - Condiçōes das eliminaçōes intestinais:

Observar o número e aspecto das evacuaçōes.

8 - Condiçōes das lesōes:

Prescrever curativos diários, observando técnicas de isolamento. Anotar a evoluçāo das lesōes e a evoluçāo do edema.

Manter irrigaçāo contínua com água oxigenada e soro fisiológico $1 / 2$ a $1 / 2$ quando indicado. 
VASCO, M.L.T. e RODRIGUES, E. - Gangrena gasosa - Assistência de enfermagem.

Rev. Bras. Enf.; DF, $30: 244-253,1977$.

9 - Manutençāo do tratamento específico e hidrataçāo parenteral: Controlar o gotejamento do soro, observar o local da infusāo venosa e a permeabilidade do catéter. Quando o paciente apresenta veias difíceis, há necessidade de dissecçāo de veias periféricas, ou passagem de "intracath" em veias profundas.

Observar quaisquer reaçōes após a aplicaçāo do soro antigangrenoso, como:

- exantema, febre, urticária, dores articulares e musculares e choque anafilático.

Comunicar imediatamente ao médico qualquer anormalidade.

10 - Manutençāo da assistência psicológica, religiosa e social:

Todos os tratamentos devem ser cuidadosamente explicados ao paciente antes de serem executados, tentando-se assim aliviar a sua tensāo; prestar esclarecimentos sobre a moléstia, sua evoluçāo e prognóstico. Valorizar as manifestaçōes de pudor do paciente, principalmente quando se trata de lesões genitais. Promover recreaçāo e lazer de acordo com o grau de consciência, condiçōes físicas e preferências do paciente.

Promover terapia de apoio, atendendo suas necessidades religiosas e psiquicas individuais, sem criar graus de dependência.

Se apresentar problemas sociais, solicitar a presença do assistente social para que se tomem resoluçōes concernentes ao caso.

11 - Condiçōes do ambiente e suprimentos:
Manter o ambiente arejado e desodorizado.

Programar a manutençāo de suprimentos necessários à utilização da técnica de isolamento.

12 - Educaçāo das visitas:

Instruir as visitas quanto às precauçōes a serem observadas no quarto do paciente, a saber:

a) nāo tocar no paciente;

b) nāo tocar nas roupas;

c) lavar as mãos ao deixar o quarto.

\section{CONCLUSAO}

A açāo da enfermeira é essencial no diagnóstico precoce de uma gangrena gasosa, através da observaçāo cuidadosa durante os curativos das lesōes traumáticas, pós cirúrgicas, queimaduras e outras; dai a necessidade de que esta tenha conhecimentos científicos básicos em relaçāo à doença, sua evoluçāo e tratamento.

Os aspectos mencionados quanto à assistência de enfermagem sāo aspectos gerais a serem observados. Devemos ressaltar entretanto, que a principal característica de um plano assistencial é a sua individualidade.

Os casos suspeitos devem ser isolados até que se tenha a confirmaçāo diagnóstica e se inicie a terapêutica específica, pois quanto mais rápida for iniciada, melhor será o prognóstico.

Quando se instala o isolamento na unidade, de internaçāo do paciente, a vigilância aos princípios de assepsia deve ser rígida, assim como o preparo técnico da equipe que irá cuidar do paciente.

Devem ser programados cursos de reciclagem sobre conceitos, tipos e técnicas utilizadas em isolamento, assim como noçōes sobre a moléstia. 
VASCO, M.L.T. e RODRIGUES, E. - Gangrena gasosa - Assistência de enfermagem. Rev. Bras. Enf.; DF, 30 : 244-253, 1977.

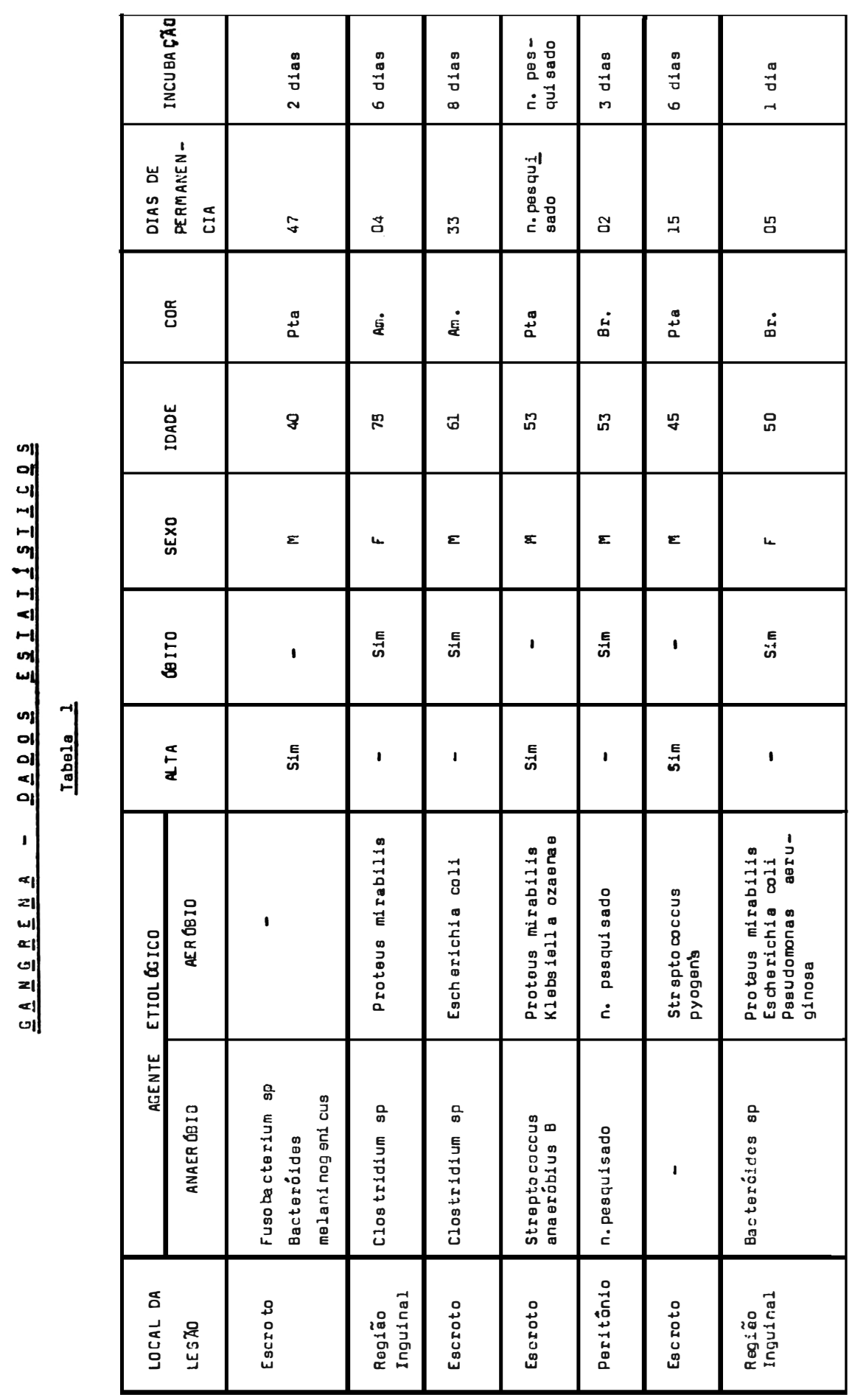


VASCO, M.L.T. e RODRIGUES, E. - Gangrena gasosa - Assistência de enfermagem.

Rev. Bras. Enf.; DF, 30 : 244-253, 1977.

DIFERENCIAC茴 DE INFECC UES GASOSAS

DE PELE E TECIDOS MOLES

Tabola II

\begin{tabular}{|c|c|c|c|c|}
\hline CRITERIOS & $\begin{array}{l}\text { Celulite por } \\
\text { aneeróbios }\end{array}$ & $\begin{array}{l}\text { Gangrena por } \\
\text { infecção vascu- } \\
\text { lar }\end{array}$ & $\begin{array}{l}\text { Mionecroses por } \\
\text { Clostridium }\end{array}$ & $\begin{array}{l}\text { miosites por } \\
\text { estreptococcus }\end{array}$ \\
\hline incubação & $\begin{array}{l}\text { cerca de } 3 \\
\text { dias }\end{array}$ & $\begin{array}{l}\text { cerca de } 5 \\
\text { dias ou maia }\end{array}$ & $\begin{array}{l}\text { em geral menos } \\
\text { de } 3 \text { diae }\end{array}$ & $3-4$ dias \\
\hline início & gradual & gradual & agudo & $\begin{array}{l}\text { oub-audo ou } \\
\text { ingidio80 }\end{array}$ \\
\hline Toxemia & $\begin{array}{l}\text { nenhuma ou } \\
\text { discreta }\end{array}$ & $\begin{array}{l}\text { nenhuma ou } \\
\text { mínima }\end{array}$ & muito grave & $\begin{array}{l}\text { grave, após } \\
\text { algum tempo }\end{array}$ \\
\hline dor & ous ente & variével & muito forte & $\begin{array}{l}\text { variável como } \\
\text { regra bastan- } \\
\text { to severa }\end{array}$ \\
\hline edema & $\begin{array}{l}\text { nenhum ou } \\
\text { discreto }\end{array}$ & $\begin{array}{l}\text { mitas vezea } \\
\text { intenso }\end{array}$ & intenso & intenso. \\
\hline pele & $\begin{array}{l}\text { pequenas al te } \\
\text { terações }\end{array}$ & $\begin{array}{l}\text { descolorida, } \\
\text { mitas vezes }\end{array}$ & $\begin{array}{l}\text { tenaa, frequen- } \\
\text { temente muito } \\
\text { esbrenquiçada o } \\
\text { cr marrom bronzé }\end{array}$ & $\begin{array}{l}\text { tensa, frequen } \\
\text { temente cor de } \\
\text { cobre }\end{array}$ \\
\hline exuda to & $\begin{array}{l}\text { nenhum ou } \\
\text { discreto }\end{array}$ & nenhum & $\begin{array}{l}\text { variável. Pode } \\
\text { ser abundante } \\
\text { earoso e impre } \\
\text { grado de sangue }\end{array}$ & $\begin{array}{l}\text { mito abundan } \\
\text { te a seropuru } \\
\text { lento }\end{array}$ \\
\hline gغ́8 & abundante & abundante & $\begin{array}{l}\text { raramente pronun } \\
\text { ciado, exceto om } \\
\text { fases finais da } \\
\text { moléstia }\end{array}$ & muito discreto \\
\hline$\infty \circ$ & fétido & fétido & $\begin{array}{l}\text { variável. Pode } \\
\text { estar ausente, } \\
\text { frequ en temente } \\
\text { é adocicado. }\end{array}$ & $\begin{array}{l}\text { mito discreto } \\
\text { erequentemente } \\
\text { ácido (azedo) }\end{array}$ \\
\hline musculatura & não alterada & morta & $\begin{array}{l}\text { altsraçöes mar - } \\
\text { canter }\end{array}$ & $\begin{array}{l}\text { iaicialmente } \\
\text { pequena alte } \\
\text { ração e ede- } \\
\text { ma }\end{array}$ \\
\hline
\end{tabular}


VASCO, M.L.T. e RODRIGUES, E. - Gangrena gasosa - Assistência de enfermagem. Rev. Bras. Enf.; DF, 30 : 244-253, 1977.

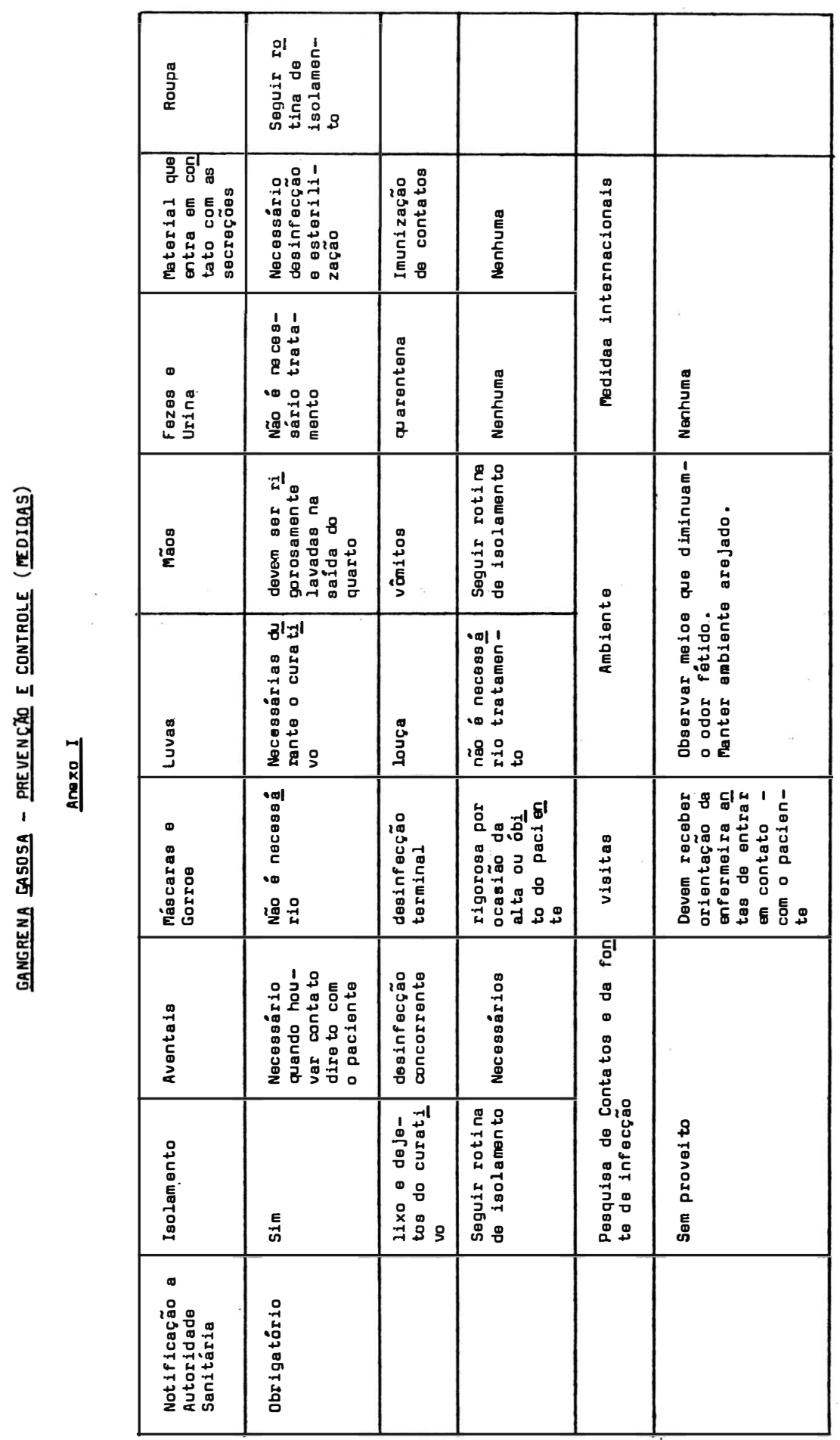


VASCO, M.L.T. e RODRIGUES, E. - Gangrena gasosa - Assistência de enfermagem.

Rev. Bras. Enf.; DF, $30: 244-253,1977$.

\section{A N EXO I I}

\section{SORO ANTI-GANGRENOSO-BUTANTA}

E um soluto purificado e concentrado, pela digestāo péptica de imunoglubulinas específicas do soro de cavalos hiperimunizados contra as toxinas e corpos bacilares das espécies bacterianas causadoras de gangrena gasosa. Este produto é aferido in vivo em unidades internacionais e contém os seguintes titulos por ampolas de $20 \mathrm{ml}$ :

- antitoxina perfringens $-2.000 \mathrm{U}$.I.

- antitoxina víbrio sépticus -2.000 U.I.

- antitoxina oedematiens -3.000 U.I.

-- INDICAÇAO

Indicado para a prevençāo e o tratamento da gangrena gasosa.

- DOSES

A dose inicial é de 4 a 8 ampolas de $20 \mathrm{ml}$. por via muscular ou preferivelmente, metade desta dose por via intravenosa, e a outra metade por via intramuscular.

A repetiçāo da dose far-se-á de acordo com a evoluçāo clínica.

\section{- REAÇOES E SUA PREVENÇÃO}

\section{1 - Reação anafilática:}

A sensibilidade anafilática às proteínas do soro de cavalo pode determinar um choque anafilático no ato da administraçāo do soro. Antes da administraçāo deve-se fazer o teste da sensibilldade. Diluise o soro específico a 1:10 em soluçāo físiológica.

Instilar num dos olhos 1 a 2 gotas. No outro olho, para controle, 1 a 2 gotas de soro fisiológico.

A reaçāo positiva (alergia) consiste no aparecimento de nitida vermelhidāo a lacrimejamento, dentro de 15 minutos, no olho instilado com soro diluído; as reaçōes mais intensas sāo paralisadas mediante instilaçāo de uma gota de soluto milesimal de cloridrato de adrenalina.

No caso da reaçāo ser negativa, pode-se fazer a injeçāo subcutânea ou intravenosa sem maiores precauçōes.

Caso a reaçāo seja positiva deve-se:

- injetar o soro apenas por via parenteral, observando os seguintes cuidados:

- colocar um garrote frouxo, pronto para ser apertado, acima do ponto escolhido para a injeçāo;

- ter à māo, ampola de adrenalina a 1:1.000; 
VASCO, M.L.T. e RODRIGUES, E. - Gangrena gasosa - Assistência de enfermagem.

Rev. Bras. Enf.; DF, 30 : 244-253, 1977.

- injetar intradermicamente 0,25 a $0,50 \mathrm{ml}$. de soro puro.

Esperar 10 minutos, caso nāo haja reaçāo, injetar o restante da dose por via intramuscular.

- havendo reaçāo geral (sintomas de colapso periférico), apertar o garrote a fim de sustar a absorçāo rápida e injetar $0,5 \mathrm{ml}$. de adrenalina por via subcutânea.

- cessado a reaçāo, afrouxar pouco a pouco o garrote; injetar novamente $0,5 \mathrm{ml}$. de adrenalina; administrar lentamente por via intramuscular o resto do soro em doses fracionadas e creseentes $(0,50-1,0-2,0-4,0 \mathrm{ml}$. , etc. $)$.

Durante essas operaçōes, controlar o estado geral do paciente (P.A., P. e T.), deixando de injetar, apertando o garrote e inoculando adrenalina; ao menor sintoma de choque, parar, recomeçar tudo novamente até se conseguir administrar a dose necessária.

Todos estes procedimentos devem ser efetuados sob vigilância médica.

\section{2 - Doença Sérica:}

E ocorrência menos encontradiça nos soros, purificados pela digestão péptica, dependendo sua freqüência, do teor total de proteinas inoculadas. E de manifestação tardia (6 a 11 dias após a aplicação) e caracteriza-se por:

- exantema que se inicia no ponto de inoculaçāo, para depois se generalizar, acompanhado de febre, urticária, dores articulares e musculares, sendo recomendável, medicaçāo sintomática, associada aos anti-histamínicos sintéticos.

\section{BIBLIOGRAFIA}

1. ALTEMIER W. and Fullen W. - Prevention and Treatment of Gasgangrene, inn Jama, aug., 1971 - vol. 217, n. 0.

2. AMATO, V. - Doenças Transmissíveis 356 à $357-1 .^{\mathrm{a}}$ ed. 1974.

3. FINDLEY G. H. - More about gangrenes, in Nursing Times, febraury, 15, 1973.

4. FINEGOLD, S. - Monograph on Anaerobic infections; published by the UPJOHN COMPANY, Kalamazoo, Michigan, 1972.
5. HUGHES, E. M. - A patient with Gas Gangrene, inn Nursing Times, february 15, 1973.

6. MAUDSLEY, R.H. - Gas Gangrene and itsmanagement, inn Nursing Times, february 15, 1973.

7. PARROT, A. J. - Fournier's gangrene of the Scrotum, inn Nursing Mirror, 29, november 1968.

8. VERONESI, R. - Doenças Infecciosas e Parasitárias - 497 à 499 - Guanabara Koogan - 5. ed. - 1972.

9. Bula do Instituto Butantå sobre soro antigangrenoso. 